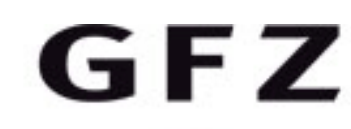

Helmholtz-Zentrum

P O T S A M

Originally published as:

Janssen, C., Wirth, R., Rybacki, E., Naumann, R., Kemnitz, H., Wenk, H.-R., Dresen, G. (2010): Amorphous material in SAFOD core samples (San Andreas Fault): Evidence for crush-origin pseudotachylytes?. - Geophysical Research Letters, 37, L01303

DOI: 10.1029/2009GL040993 


\title{
Amorphous material in SAFOD core samples (San Andreas Fault): Evidence for crush-origin pseudotachylytes?
}

\author{
C. Janssen, ${ }^{1}$ R. Wirth, ${ }^{1}$ E. Rybacki, ${ }^{1}$ R. Naumann, ${ }^{2}$ H. Kemnitz, ${ }^{1}$ H.-R. Wenk, ${ }^{3}$ \\ and G. Dresen ${ }^{1}$ \\ Received 15 September 2009; revised 11 November 2009; accepted 24 November 2009; published 5 January 2010.
}

[1] Several types of amorphous material in ultracataclastic core samples recovered from $3194 \mathrm{~m}$ and $3294 \mathrm{~m}$ depth of the main bore hole of the San Andreas Fault Observatory at Depth are identified and described with transmission electron microscopy and scanning electron microscopy. We observed (1) amorphous material on a slickenside surface, (2) glassy bands contained in an ultracataclastic matrix and (3) amorphous rims surrounding quartz or feldspar clasts. Chemical analyses of the amorphous material reveal that silica content is slightly enriched or similar as in the adjacent matrix. We suggest that all amorphous material was formed by comminution of clasts (crush-origin pseudotachylytes) rather than by melting (melt-origin pseudotachylytes). The observed amorphous phases may act as lubricating layers that reduce friction in the San Andreas Fault. Citation: Janssen, C., R. Wirth, E. Rybacki, R. Naumann, H. Kemnitz, H.-R. Wenk, and G. Dresen (2010), Amorphous material in SAFOD core samples (San Andreas Fault): Evidence for crush-origin pseudotachylytes?, Geophys. Res. Lett., 37, L01303, doi:10.1029/2009GL040993.

\section{Introduction}

[2] The San Andreas Fault Observatory at Depth (SAFOD) is a $3.2 \mathrm{~km}$ deep borehole, drilled into the San Andreas Fault Zone (SAF) to study directly the structure and composition of an active segment [Hickman et al., 2007]. Within the SAFOD project some of the most exciting questions about faulting have been addressed. The overall scientific purpose is framed around the question "Why are the SAF and some other major faults absolutely or relatively weak?" Previously proposed explanations for the anomalously low shear strength of the SAF include elevated fluid pressure or the presence of minerals with low friction coefficient [Hickmann et al., 2004; Schleicher et al., 2009]. However, evidence for significantly elevated fluid pressure reducing the strength of the fault is still controversial [Mittempergher at al., 2009; Zoback et al., 2007] and alternative explanations focus on specific minerals or mineralreactions [Schleicher et al., 2009]. One possible explanation for the apparent weakness of fault rocks is the discovery of talc bearing serpentinites in SAFOD cuttings [Moore and

\footnotetext{
${ }^{1}$ Department of Geodynamics and Geomaterials, GFZ German Research Centre for Geosciences, Potsdam, Germany.

${ }^{2}$ Department of Chemistry and Material Cycles, GFZ German research Centre for Geosciences, Potsdam, Germany.

${ }^{3}$ Department of Earth and Planetary Science, University of California, Berkeley, California, USA.
}

Copyright 2010 by the American Geophysical Union. 0094-8276/10/2009GL040993\$05.00
Rymer, 2007]. However, Bradbury et al. [2007] and Schleicher et al. [2009] could not identify significant amounts of talc or serpentine in the fault gouge. Instead they found localized precipitation of hydrous mixed-layered clay minerals with higher smectite-content as thin coatings on fractured clasts and polished slip surfaces [Hickman et al., 2008; Schleicher et al., 2009]. But clay minerals alone cannot account for the apparent weakness of the San Andreas Fault, because laboratory experiments yield friction coefficients that are too high [Moore et al., 1997].

[3] Here we describe the previously undetected presence of amorphous phases in two samples. We suggest that the occurrence of amorphous material within the fault rocks may contribute significantly to the strength reduction of the San Andreas Fault.

\section{SAFOD Setting}

[4] SAFOD is located in central California at the transition between the creeping segment of the SAF and the Parkfield segment (Figure 1a). The geology of the SAFOD drill site (Figure 1b) is dominated by transpression along the SAF, which juxtaposes the Salinian granitic basement in the SW (Pacific plate) against the Franciscan block on the NE (North American plate) [Bradbury et al., 2007]. The SAFOD main borehole encountered at least four major geological units during drilling (Figure 1c). After passing through near-surface Quaternary and Tertiary sediments and the subjacent Salinian granite, arkosic sediments were encountered beneath the Buzzard Canyon fault [Bradbury et al., 2007] (Figure 1b). Further east (approximately $1200 \mathrm{~m}$ NE of the drill site) the lithology changes abruptly from arkosic sediments of the Salinian terrane (Pacific plate) to claystones and siltstones of the Great Valley/Franciscan terrane (North American plate). The lithological boundary possibly marks an ancestral trace of the SAF. Multiple faults were crossed during drilling, including two actively creeping strands of the SAF revealed by casing deformation at depths of $3194 \mathrm{~m}$ and $3301 \mathrm{~m}$ [Bradbury et al., 2007].

\section{Methods}

[5] Samples from SAFOD Phase III were investigated with different analytical techniques. Powder X-ray patterns were collected using a Siemens D5000 powder diffractometer. The Rietveld algorithm BGMN was used for quantitative analysis [Bergmann et al., 1998]. Microstructures in fault rock samples were first analyzed optically and using a Zeiss FESEM (Scotty-type field emission scanning electron microscope).

[6] From optical thin sections and SEM micrographs we selected samples for TEM studies that were prepared with a 


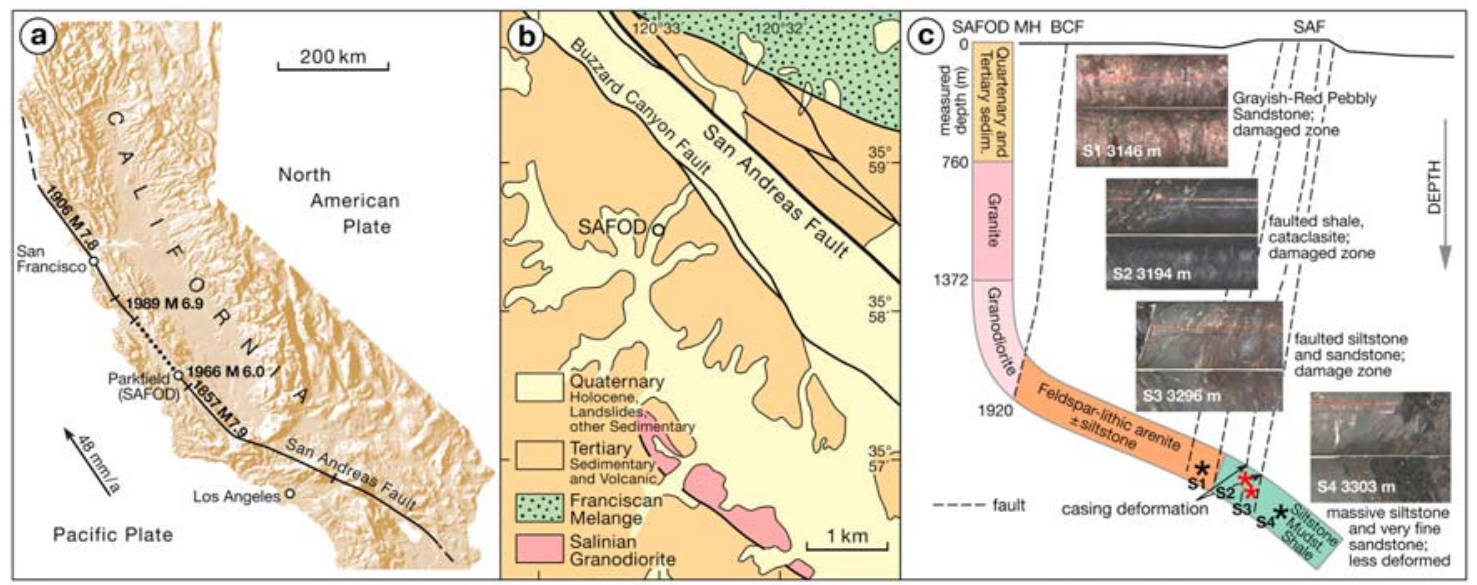

Figure 1. (a) The San Andreas Fault with the SAFOD drill site. The arrow shows the sense of plate movement [Hickmann et al., 2004]. Some major historical earthquakes are indicated. The dotted line characterizes the creeping segment. (b) Geological map of the drilling site [after Bradbury et al., 2007]. (c) Simplified depth profile of the SAFOD MH (Main Hole) with different rock lithologies and sample positions. The red stars mark the positions of the two samples with amorphous material (modified after Bradbury et al. [2007; also Schleicher et al., 2009]). BCF is Buzzard Canyon fault; SAF is San Andreas Fault.

focused ion beam (FIB) device at GFZ Potsdam (FEI FIB200TEM). TEM foils $15 \times 10 \mu \mathrm{m}$ in size and $0.150 \mu \mathrm{m}$ thick were sputtered from thin sections using accelerated Ga-ions (30 keV). FIB technique implants Ga-ions into the target material. Energy dispersive X-ray analysis always contains minor amounts of $\mathrm{Ga}$ in the X-ray intensity spectrum. Details of the FIB technique are given elsewhere [Wirth, 2004, 2009]. TEM was performed using a FEI Tecnai G2 F20 X-Twin transmission electron microscope (TEM/AEM) equipped with a Gatan Tridiem energy filter, a Fishione high-angle annular dark field detector (HAADF) and an energy dispersive X-ray analyzer (EDX). EDX spectra usually were acquired in scanning transmission mode (STEM) scanning the electron beam in a pre-defined window of approximately $50 \mathrm{~nm} \times 50 \mathrm{~nm}$ to minimize mass loss during spectrum acquisition. At the very beginning of the TEM investigation, all foils were illuminated with a defocused wide electron beam to avoid amorphization of the sample by electron irradiation while checking for the presence of amorphous material. Tilting of the sample under those conditions would show areas without any diffraction contrast thus indicating local non-crystallinity. Sample composition was estimated using a Bruker-axs D8 X-ray microdiffractometer.

\section{Samples}

[7] In this study we analyzed microstructures and composition of four samples from SAFOD phase III cores (S1, S2, S3 and S4). Samples were recovered from core sections located close to or within zones of active deformation (Figure 1c). However, amorphous material was found in only two samples (S2 and S3). These samples are described in detail below. We therefore describe these samples in detail. Both samples likely belong to the Great Valley sequence [Bradbury et al., 2007].

[8] Sample S2 was collected at $3194 \mathrm{~m}$ MD. This section of the core is expected to coincide with a drilling section in which the casing is being currently deformed. It thus represents an actively creeping portion of the SAF. The highly foliated shale gouge is composed of a brown, fine grained calcite-bearing clay matrix containing quartz and feldspar clasts. Pervasive shearing is defined by dark seams in the matrix and preferred orientation of clasts. Numerous pressure solutions seams and authigenic clay minerals indicate extensive fluid-rock interactions and dissolutionprecipitation processes [see Hickman et al., 2008; Schleicher et al., 2009]. The latest calcite vein generation overprints the fault related fabric.

[9] Sample S3 is from $3296 \mathrm{~m} \mathrm{MD,} \mathrm{i.e.} \mathrm{the} \mathrm{sample} \mathrm{is}$ located at about $5 \mathrm{~m}$ distance to the active deformation zone at $3301 \mathrm{~m}$. The sample shows a polished slip surface with slickensides. Sample S3 consists of a dark-brown fractured and fine-grained scaly matrix with a higher percentage of smectite/illite compared to sample S2 (Table 1). In addition, chlorite is a major mineral constituent of the sample. Similar to sample S2, seams of insoluble material (pressure solution relicts) and authigenic clay minerals suggest considerable activity of dissolution precipitation processes.

\section{Description of Amorphous Material}

[10] Amorphous phases were found in two samples, sample S2 (9\%) and sample S3 (4\%, Table 1). According to their appearance we distinguish between (1) amorphous

Table 1. Composition of Samples 2 and 3

\begin{tabular}{lcc}
\hline \multicolumn{1}{c}{ Minerals } & Sample 2 [in vol.\%] & Sample 3 [in vol.\%] \\
\hline quartz & 50 & 30 \\
illite/smectite & 22 & 38 \\
albite & 13 & 10 \\
calcite & 5 & 3 \\
analcime & 1 & 0 \\
chlorite & 0 & 12 \\
haematite & 0 & 3 \\
amorphous material & 9 & 4 \\
\hline
\end{tabular}


matrix materials at a slickenside surface, (2) amorphous rims surrounding quartz or feldspar clasts and (3) glassy bands in an ultracataclastic matrix. The amorphous phases are identified using TEM studies.

\subsection{Amorphous Matrix Material}

[11] SEM imaging shows that the polished and smeared slip surface of sample S3 is covered by a thin film of hydrous mixed-clay minerals (Figure 2a). Schleicher et al. [2009] suggested localized precipitation of hydrous mixedclay minerals that grow preferentially on polished fault surfaces (Figure 2a, inset).

[12] The thin coatings have been shown to be amorphous by TEM diffraction patterns that display amorphous rings (see Figure 2b, inset). Nanoscale chlorite crystals with tabular shape are found in the amorphous material. TEM-EDX analyses of the adjacent matrix reveal a mixture of quartz and sheet silicates. With respect to the adjacent matrix the amorphous material is slightly enriched in silica at the expense of magnesium (Figure 2c).

\subsection{Amorphous Rims}

[13] In sample S2, a few small mineral clasts $(<1 \mu \mathrm{m})$ have been found surrounded by rims of amorphous material (Figure 2d). In dark and bright field TEM images, these clasts, mostly quartz and very rarely feldspar, appear eroded or etched (Figure 2e). The rims are between 50 and $100 \mathrm{~nm}$ wide and contain extremely fine-grained rutile/anatase crystals. EDX analyses of rims indicate a similar chemical composition of clasts and surrounding rims (Figure 2f). Based on optical microscopy, the presence of quartz clasts with opaque rims was also observed in granitic mylonites [Lin, 1994].

\subsection{Glassy Bands}

[14] Some dark or brown fault-related branching veins in the ultracataclastic matrix of sample S2 resemble micropseudotachylytes [see Snoke et al., 1998; Blenkinsop, 2000; Ujiie et al., 2007]. These veinlets are thin $(<1 \mathrm{~mm})$ and appear homogeneous. They form an anastomosing system subparallel to the foliation embedded in the ultracataclasite matrix. The boundary between veins and host rock is sharp and distinct. Under cross-polarized light, the dark, extremely fine-grained matrix is optically isotropic suggesting a glassylike matrix (Figure 3a). However, the matrix contains no visible melt structures such as vesicles, amygdules, microlites, spherulites or sulfide droplets.

[15] In SEM images the dark veins reveal a glassy-like coating, covering very fine matrix grains (Figure 3b). Larger subangular to subrounded quartz and albite grains (rarely rutile/anatase) have also been observed but without the coating.

[16] At the TEM scale, glassy band structures have been found within the dark veins (Figures $3 \mathrm{c}$ and $3 \mathrm{~d}$ ). The presence of amorphous material is verified by a) absence of any diffraction contrast during tilting the sample under defocused electron beam conditions; b) the electron diffraction patterns of these bands, which are characterized by a broad diffuse scattering intensity (amorphous ring in Figure 3c, inset). The width of the amorphous bands varies between 100 and $300 \mathrm{~nm}$, and it frequently exceed $1 \mu \mathrm{m}$ in length. In some places, the contact between band and matrix is sharp and distinct, whereas elsewhere a gradual transition to an extremely fine-grained matrix is observed (grain size < $50 \mathrm{~nm}$ ). The bands are slightly enriched in silica with respect to the adjacent matrix (Figure 3e). Similar glassy bands in fault rocks have been described by Wenk [1978] and Borradaile et al. [1982].

\section{Origin of Amorphous Material}

[17] Amorphous material in deformed rocks is often termed pseudotachylyte [Shand, 1916] and its formation is classically attributed to melting due to impact or frictional heating. By now, however, two main mechanisms of pseudotachylyte (PT) formation in fault zones have been suggested, one by frictional melting [e.g., Sibson, 1975], the other one by comminution [e.g., Wenk, 1978]. The latter process includes solid-state phase transformation and changes in the physical and chemical properties of the material [Ozawa and Takizawa, 2007]. Melt origin PT types contain melt textures such as glassy material, dendritic crystallites, vesicles and amygdules, spherulites and sulfide droplets [e.g., Magloughlin and Spray, 1992; Lin, 1994; Ujiie et al., 2007, Wenk et al., 2000]. In contrast, crushorigin PT types show none of these characteristics [Otsuki et al., 2009]. In addition, also laboratory shear experiments have shown that glass and other amorphous material can be formed not only via the rapid cooling of melt, but also by amorphization of quartz in the presence of water [e.g., Goldsby and Tullis, 2002; Di Toro et al., 2004].

[18] The glass phases detected by TEM in our samples show no conclusive evidence indicating either melt origin or crush origin of the amorphous material. We note however, melt textures as described above have not been observed.

[19] A further distinguishing feature characterizing the origin of pseudotachylites may be the composition of the amorphous material compared to the surrounding matrix. Several studies indicate that melt-origin PT types contain less $\mathrm{SiO}_{2}$ than the host rock [e.g., Lin, 1994], whereas in crushorigin types the amorphous material is enriched in silica probably because of a preferential gelation of quartz [Otsuki et al., 2009]. In our samples, EDX analyses indicate that either the glassy matrix compositions are similar to those of adjacent matrix or silica is slightly enriched in the amorphous material. In view of these observations, we suggest that the amorphous material observed here may be related to

Figure 2. (a) SEM micrograph illustrates a fault surface of sample 3 covered by silica thin-film coatings. The inset shows newly-formed clay minerals with a characteristic flaky shape. (b) TEM bright field image illustrates the presence of authigenic chlorites in an amorphous matrix. The inset shows the broad diffuse scattering intensity of amorphous material additional to individual reflections from crystalline material in the diffraction pattern. (c) EDX spectra of adjacent matrix and amorphous material. (d) TEM HAADF image of a Quartz grain surrounded by a small amorphous rim containing rutile/ anatase crystals (bright crystals). The inset shows the diffraction pattern of the rim. (e) TEM dark field image shows an eroded and etched quartz clast. (f) EDX spectra of clast and amorphous rim. 

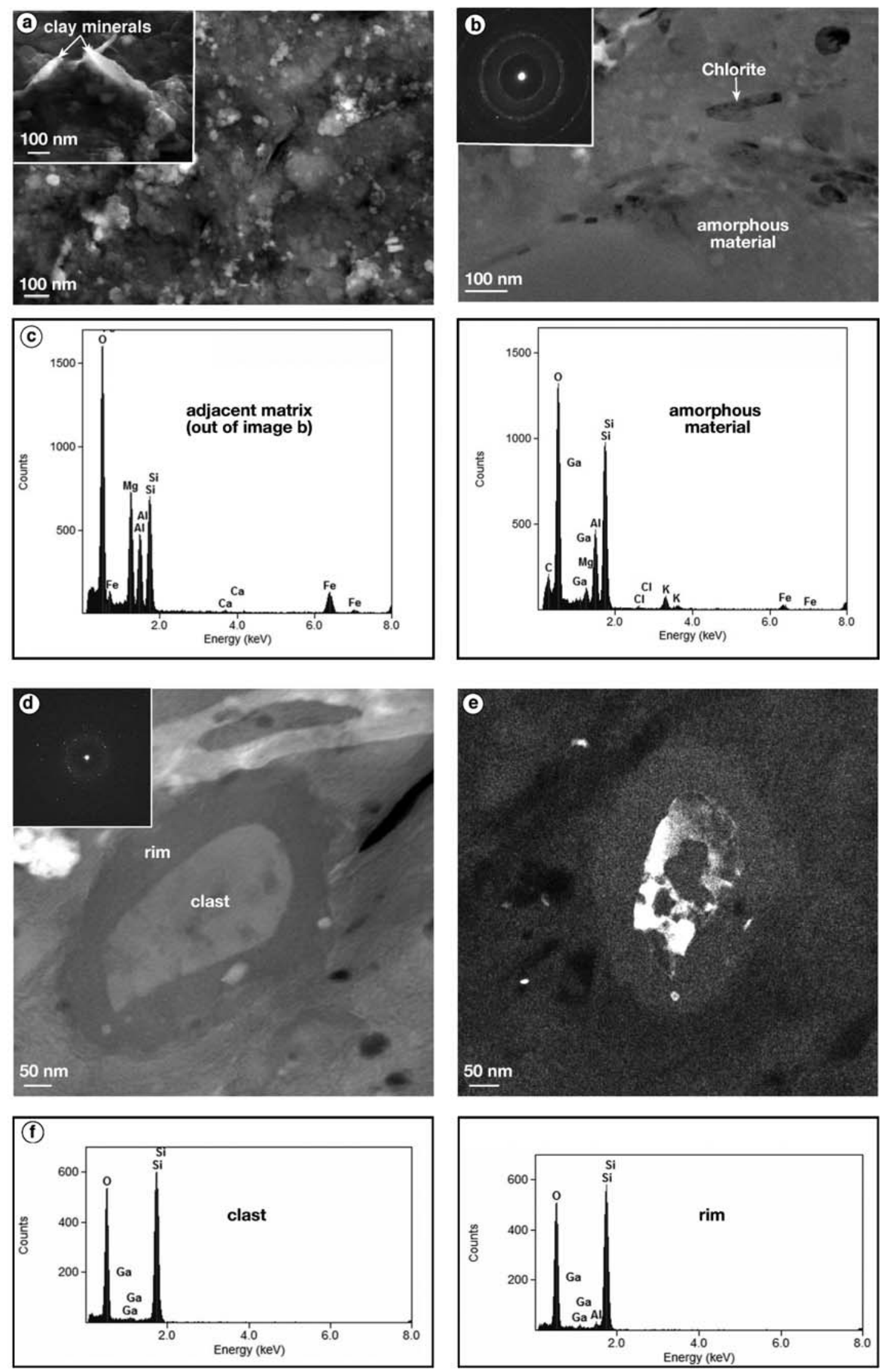

Figure 2 

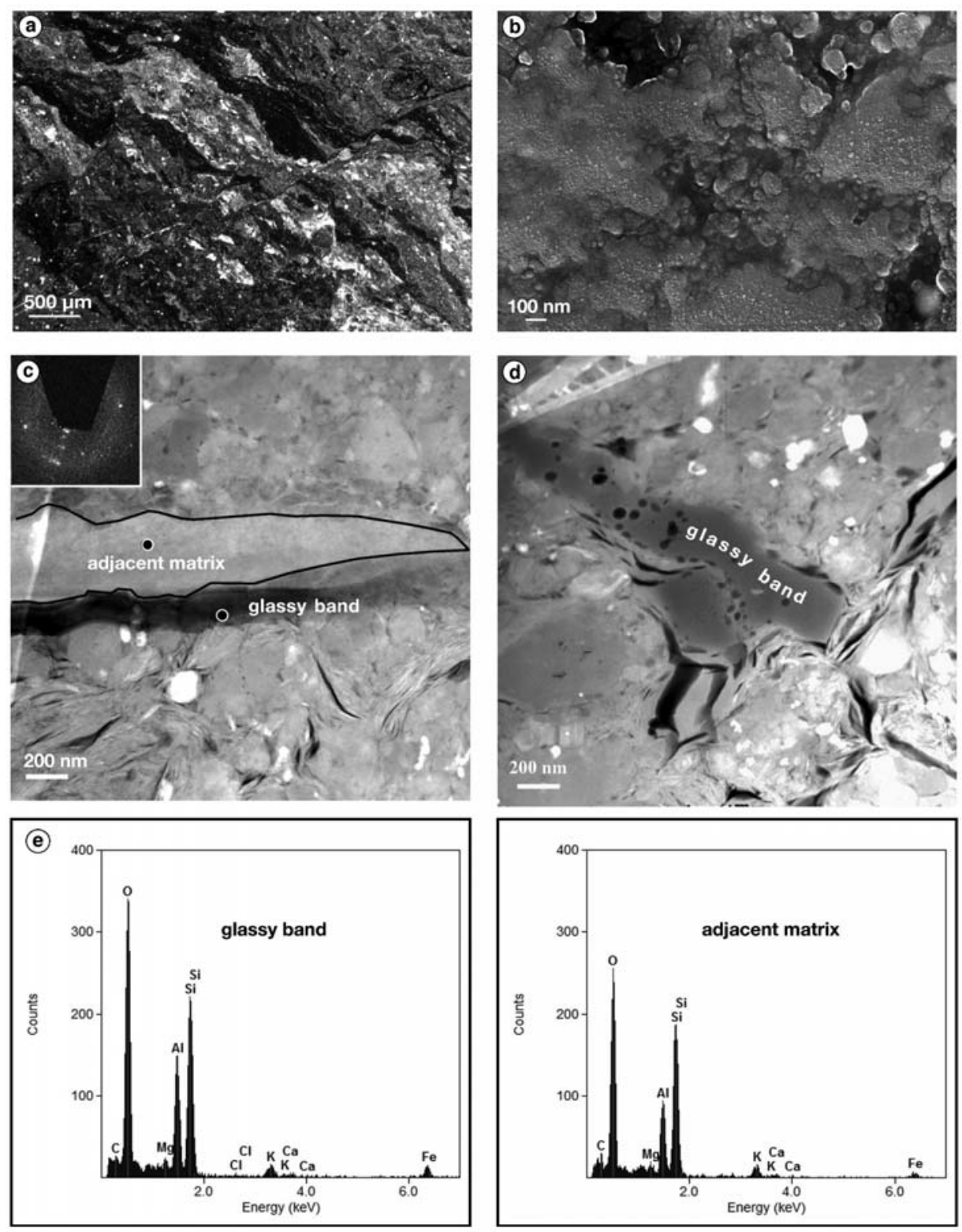

Figure 3. (a) Photomicrograph of dark veins in the foliated matrix of sample 2 under crossed polarizer. (b) SEM image reveals glass-like coating (c) TEM high-angle annular dark field (HAADF) image of amorphous layer in the ultracataclastic vein matrix. The upper-left corner shows diffuse broad scattering intensity from non-crystalline material in addition to some individual reflections from crystals. (d) TEM HAADF image of glassy band revealing pores not present initially. The pores (dark patches) in the glass result from electron beam damage in TEM evolving progressively with time. (e) EDX spectra acquired from glassy band and host rock material.

a crushing and comminution process rather than to rapid cooling of melt.

\section{Geophysical Implications}

[20] Irrespective of the origin of the amorphous material its presence may result in a significant strength reduction. For example, laboratory shear sliding experiments on silicate rocks at different slip rates have shown that the amorphization, gel formation and comminution under wet conditions may be an important weakening mechanisms during faulting [Goldsby and Tullis, 2002; Di Toro et al.,
2004]. Di Toro et al. [2004] suggested that the formation of thin layers of silica gel on fault surfaces may explain the low strength of major faults. The silica gel acts as a tribolayer with thixotropic behavior [Di Toro et al., 2004].

[21] It is therefore conceivable that the presence of amorphous material observed in our gouge and cataclasite samples may induce a weakening not only during seismic slip but also during creep as the amorphous phase accumulates [Goldsby and Tullis, 2002]. We suggest that the observed amorphous material behaves like a viscous fluid film lubricant that is sheared between fault surfaces and 
gouge fragments reducing friction and wear in the fault zone.

[22] In summary, the existence of amorphous material in fault rocks of the SAF may influence the strength of the fault. However, further analytical work is required to quantify the potential significance of amorphous material to explain low shear strength of the SAF.

[23] Acknowledgments. We thank Andreas Hendrich for help with drafting figures, Stefan Gehrmann for sample preparation, and Anja Schreiber for TEM foils preparation using FIB technique. This work was funded by DFG grant JA 573/4-1. Giulio Di Toro and an anonymous reviewer provided very constructive comments and suggestions that helped improve this paper.

\section{References}

Bergmann, J., P. Friedel, and R. Kleeberg (1998), BGMN-A new fundamental parameters based Rietveld program for laboratory X-ray sources, its use in quantitative analysis and structure investigations, CPD Newsl., $20,5-8$.

Blenkinsop, T. (2000), Deformation Microstructures and Mechanisms in Minerals and Rocks, Kluwer Acad., Dordrecht, Netherlands.

Borradaile, G. J., M. B. Bayly, and C. M. Powell (1982), Atlas of Deformational and Metamorphic Rock Fabrics, Springer, Berlin.

Bradbury, K. K., D. C. Barton, J. G. Solum, S. D. Draper, and J. P. Evans (2007), Mineralogical and textural analyses of drill cuttings from the San Andreas Fault Observatory at Depth (SAFOD) boreholes: Initial interpretations of fault zone composition and constraints on geological models, Geosphere, 3, 299-318, doi:10.1130/GES00076.1.

Di Toro, G., D. L. Goldsby, and T. E. Tullis (2004), Friction falls towards zero in quartz rock as slip velocity approaches seismic rates, Nature, 427, $436-439$.

Goldsby, D. L., and T. E. Tullis (2002), Low frictional strength of quartz rocks at subseismic slip rates, Geophys. Res. Lett., 29(17), 1844, doi:10.1029/2002GL015240.

Hickmann, S., M. Zoback, and W. Ellsworth (2004), Introduction to special section: Preparing for the San Andreas Fault Observatory at Depth, Geophys. Res. Lett., 31, L12S01, doi:10.1029/2004GL020688.

Hickman, S., M. Zoback, W. Ellsworth, N. Bonesse, P. Malin, S. Roecker, and C. Thurber (2007), Structure and properties of the San Andreas Fault in central California: Recent results from the SAFOD experiment, Sci. Drill., Special Issue 1, 29-32.

Hickman, S., et al. (2008), Structure and composition of the San Andreas Fault in central California: Recent results from SAFOD sample analyses, Eos Trans. $A G U, 89(53)$, Fall Meet. Suppl., Abstract T53F-01.

Lin, A. (1994), Glassy pseudotachylyte veins from the Fuyun fault zone, northwest China, J. Struct. Geol., 16, 71-83, doi:10.1016/01918141(94)90019-1.

Magloughlin, J. F., and J. G. Spray (1992), Frictional meltings processes and products in geological materials: Introduction and discussion, Tectonophysics, 204, 197-206, doi:10.1016/0040-1951(92)90307-R.

Mittempergher, S., G. D. Toro, J. Gratier, J. Hadizadeh, S. A. Smith, G. Desbois, and R. Spiess (2009), Evidence of transient increase of fluid pressure in isolated patches of the San Andreas Fault in SAFOD phase III cores, Eos Trans. AGU, Fall Meet. Suppl., Abstract T52B-04, in press.
Moore, D. E., and M. J. Rymer (2007), Talc-bearing serpentinite and the creeping section of the San Andreas Fault, Nature, 448, 795-797, doi:10.1038/nature06064.

Moore, D. E., D. A. Lockner, M. Shengli, R. Summers, and J. D. Byerlee (1997), Strengths of serpentinite gouges at elevated temperatures, J. Geophys. Res., 102, 14,787-14,801, doi:10.1029/97JB00995.

Otsuki, K., T. Hirono, M. Omori, M. Sakaguchi, W. Tanigawa, W. Lin, W. Soh, and S. Rong (2009), Analyses of pseudotachylyte from Hole-B of Taiwan Chelungpu Fault Drilling Project (TCDP): Their implications for seismic slip behaviors during the 1999 Chi-Chi earthquake, Tectonophysics, 469, 13-24, doi:10.1016/j.tecto.2009.01.008.

Ozawa, K., and S. Takizawa (2007), Amorphous material formed by the mechanochemical effect in natural pseudotachylyte of crushing origin: A case study of the Iida-Matsukawa Fault, Nagano Prefecture, central Japan, J. Struct. Geol., 29, 1855-1869, doi:10.1016/j.jsg.2007.08.008.

Schleicher, A. M., L. N. Warr, and B. A. van der Pluijm (2009), On the origin of mixed-layered clay minerals from the San Andreas Fault at 2.5$3 \mathrm{~km}$ vertical depth (SAFOD drillhole at Parkfield, California), Contrib. Mineral. Petrol., 157, 173-187, doi:10.1007/s00410-008-0328-7.

Shand, S. J. (1916), The pseudotachylytes of Parijs (orange Free State), and its relation to 'trap-shotten gneiss' and 'flinty crush-rock,' $Q$. J. Geol. Soc. London, 72, 198-222, doi:10.1144/GSL.JGS.1916.072.01-04.12.

Sibson, R. H. (1975), Generation of pseudotachylite by ancient seismic faulting, Geophys. J. R. Astron. Soc., 43, 775-794.

Snoke, A. W., J. Tullis, and V. R. Todd (1998), Fault-Related RocksA Photographic Atlas, Princeton Univ. Press, Princeton, N. J.

Ujiie, K., H. Yamaguchi, A. Sakaguchi, and S. Toh (2007), Pseudotachylytes in an ancient accretionary complex and implications for melt lubrication during subduction zone earthquakes, J. Struct. Geol., 29, 599613, doi:10.1016/j.jsg.2006.10.012.

Wenk, H. R. (1978), Are pseudotachylites products of fracture of fusion?, Geology, 6, 507-511, doi:10.1130/0091-7613(1978)6<507:APPOFO> 2.0.CO;2.

Wenk, H. R., L. R. Johnson, and L. Ratschbacher (2000), Pseudotachylites in the eastern Peninsular Ranges of California, Tectonophysics, 321 , 253-277, doi:10.1016/S0040-1951(00)00064-0.

Wirth, R. (2004), A novel technology for advanced application of microand nanoanalysis in geosciences and applied mineralogy, Eur. J. Mineral., 16, 863-876, doi:10.1127/0935-1221/2004/0016-0863.

Wirth, R. (2009), Focused Ion Beam (FIB) combined with SEM and TEM: Advanced analytical tools for studies of chemical composition, microstructure and crystal structure in geomaterials on a nanometre scale, Chem. Geol., 261, 217-229, doi:10.1016/j.chemgeo.2008.05.019.

Zoback, M. D., S. H. Hickman, W. Ellsworth, D. Kirschner, N. B. Penell, J. Chery, and S. Sobolev (2007), Preliminary results from SAFOD Phase 3: Implications for the state of stress and shear localization in and near the San Andreas Fault depth in central California, Eos Trans. $A G U, 88(52)$, Fall Meet. Suppl., Abstract T13G-03.

G. Dresen, C. Janssen, H. Kemnitz, E. Rybacki, and R. Wirth, Department of Geodynamics and Geomaterials, GFZ German research Centre for Geosciences, D-14473 Potsdam, Germany. (jans@gfz-potsdam.de)

R. Naumann, Department of Chemistry and Material Cycles, GFZ German Research Centre for Geosciences, D-14473 Potsdam, Germany.

H.-R. Wenk, Department of Earth and Planetary Science, University of California, Berkeley, CA 94720-4767, USA. 